\title{
Intelligent Collaborative System Planning Of "City Cluster + Airport Group" In GBA
}

\author{
Tian Wang ${ }^{1, a}$, Jianbang Lin ${ }^{* 2, b}$ \\ ${ }^{1}$ Foreign Studies South China Business College of Guangdong University, Guangzhou, China \\ ${ }^{2}$ Nanfang College of Sun Yat-sen University, Guangzhou, China
}

\begin{abstract}
In February 2019, the Chinese government issued the outline of development planning for Guangdong-Hongkong-Macao Greater Bay Area (GBA), which required all departments in all regions to implement it in combination with the actual situation. The implementation of the "one belt and one way" strategy is inseparable from Guangdong with special geographical location and special development orientation. The rapid development of Guangdong relies heavily on the coordinated development of "city cluster + airport group" in GBA. "City cluster + airport group" in GBA will serve as the two centers, and cooperate with each other to carry out the intelligent coordinated development of different industries and the same industries around the two centers.
\end{abstract}

\section{Introduction}

GBA is not only a key node along the "one belt and one way", but also the bridgehead of The Third Eurasian Continental Bridge. GBA includes Guangzhou, Shenzhen, Foshan, Dongguan, Huizhou, Zhongshan, Jiangmen, Zhuhai, Zhaoqing, Hong Kong Special Administrative Region and Macao Special Administrative Region. Each city and administrative region has its own different location advantages and development orientation, with clear division of labor and complementary advantages in GBA. Hong Kong's finance, logistics and trade are developed, Macao's tourism and leisure have developed for a long time. Guangzhou is the regional political, economic and cultural center, Shenzhen is dominated by high-tech industries, Dongguan and Foshan establish manufacturing bases, Huizhou develops electronic information industry and world-class petrochemical industry, Zhongshan and Jiangmen mainly focus on highend equipment manufacturing, Zhaoqing is a special location, and it is the hub portal of the Pearl River Delta. Zhuhai is positioned as a bridgehead between the mainland and Macao.

Developed air logistics is an effective way to open up to the outside world, and also a transportation guarantee to promote the development of cities in GBA. The most developed areas of China's air logistics are also located in GBA. Therefore, the intelligent collaborative construction of "city cluster + airport group" in GBA complements and promotes each other.

\section{LITERATURE REVIEW}

In 1976, synergism theory was elaborated in detail.
Hermann Haken believes that each system is different with unique attributes and characteristics. It seems unrelated, but in the overall operation, the systems interact with each other and cooperate with each other, and the relationship is extremely delicate. The theory first came from the field of physics, but now it is used for reference in the field of economic management. In economic management, it is called "coordinated development theory".

G.S. Yang(2017)[1] believes that the establishment of the best communication platform is the premise of realizing the synergy of GBA city cluster. X.K. Zhao(2017)[2] proposed that GBA development and cooperation committee should be established to promote cross regional division of labor and cooperation and lead the radiation to the surrounding areas. M.B. Shen(2017)[3] believes that in the process of coordinated development of GBA, it is necessary to emphasize such aspects as joint transportation, industrial development, market co construction and system sharing. Y. Chen and Z.H. Lin(2018)[4] makes an empirical analysis on the grey correlation degree of city cluster and industries in GBA, which shows that the industrial relations among the cities in GBA are close and the structure is similar. C.S. Zhou(2018)[5] summed up four stages of regional collaborative evolution according to the growth pole theory.

In recent years, the term "airport group" appears from time to time, but there is no official specific explanation and explanation. The author thinks that airport group formed by combining several or more airport economic zones which are close to each other in region, convenient in port cooperation, and relatively close in operation mode and development orientation is airport group. In terms of airport economic development, D. Li (2014) [6] divides airport new town into professional type and

a1204821244@qq.com b*bangnfsysu@163.com 
comprehensive type according to different development orientation of airport new town. D. Zou(2014)[7] compared three modes of spatial development of airport new area.

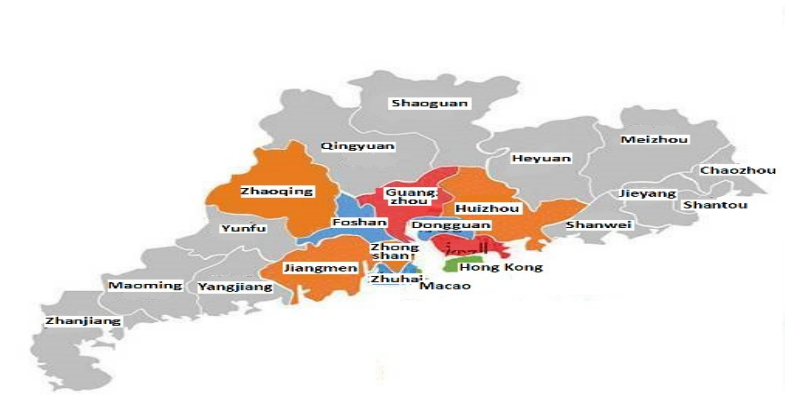

Fig1. Comparison of "city cluster + airport group" in GBA

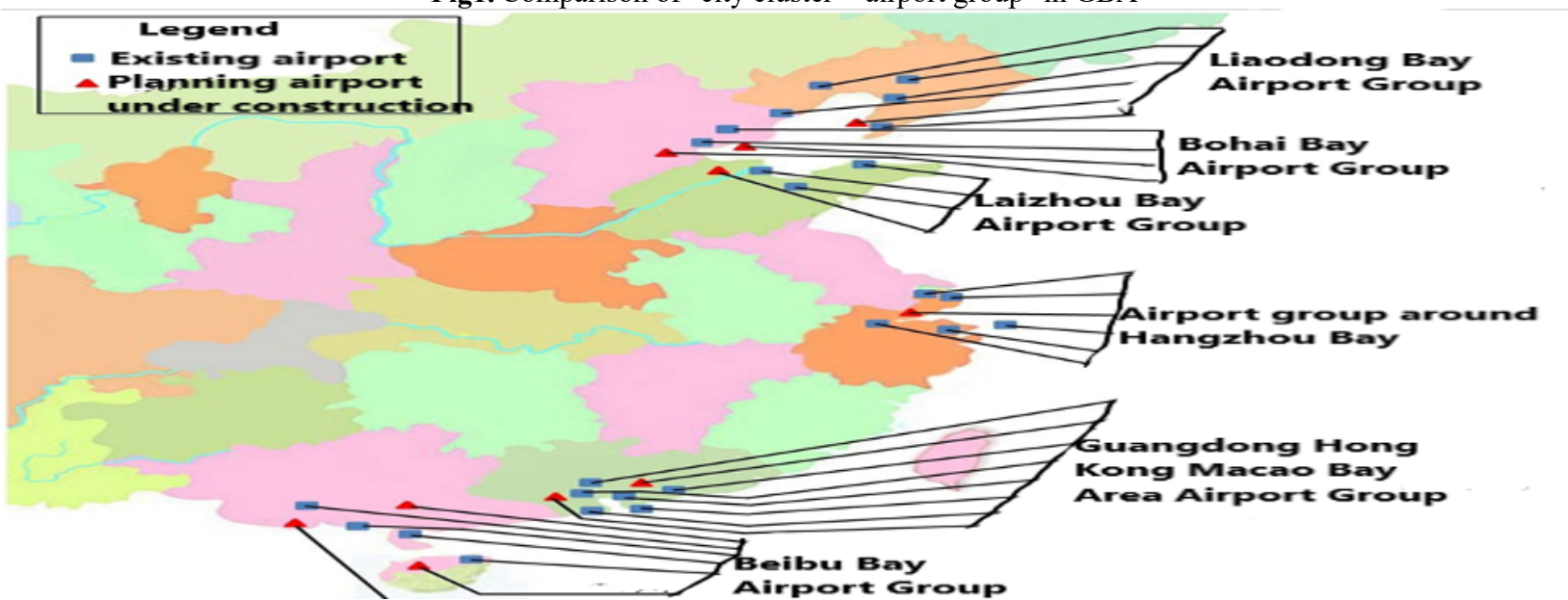

Fig2. Distribution of airport groups in China

It can be seen from Figure 3 that city cluster of GBA are concentrated in the Pearl River Delta of Guangdong Province, which is the core of the geographical location. The airports in airport group are widely distributed, mainly concentrated in the east of Guangdong Province and the Pearl River Delta. From the comparison chart, the center of "city cluster + airport group" is basically

concentrated in the Pearl River Delta, which is the same in

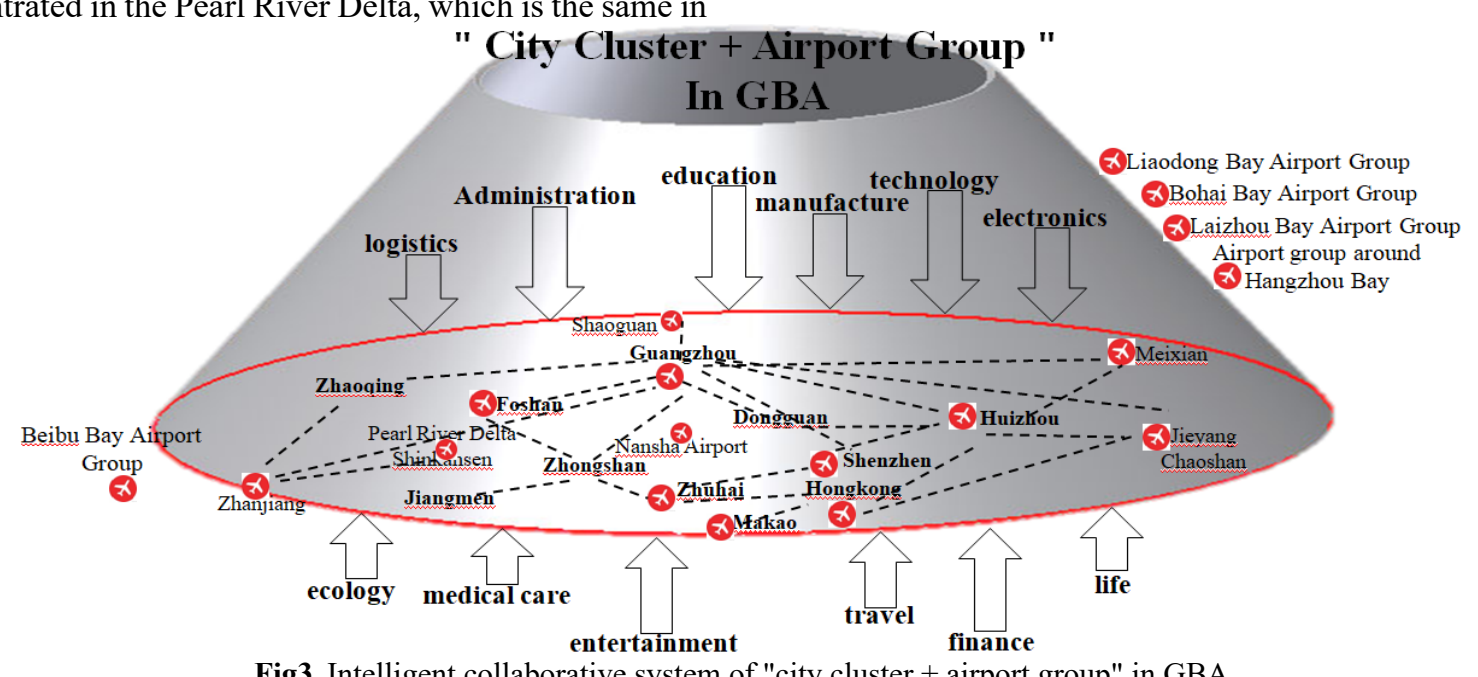

Fig3. Intelligent collaborative system of "city cluster + airport group" in GBA

\section{INTELLIGENT COLLABORATIVE SYSTEM}

\subsection{Economic indicators}

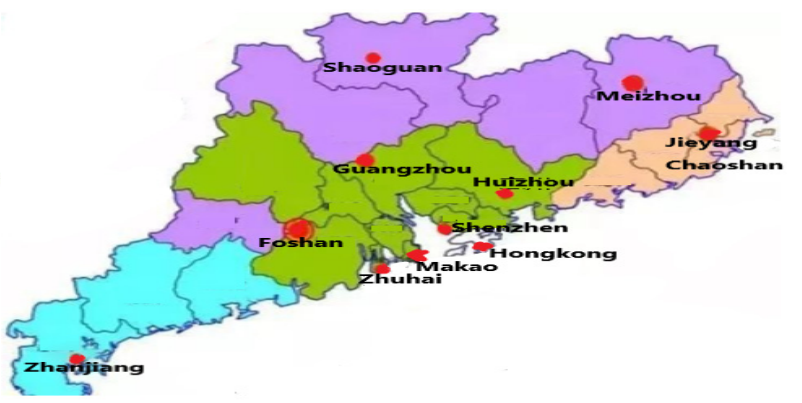

terms of location development and the same in terms of strategic planning, which can better coordinate development. In the future, with the continuous development of airport group in GBA, airport group will join forces with other airport groups to better promote the great development of the whole area, as shown in Fig.2. 


\subsection{Design of Intelligent Collaborative System for GBA}

\subsubsection{Intelligent collaboration of "city cluster +airport group"}

Guangdong speeds up the construction of the "one belt" road mainly from two centers, one is the construction of city cluster in GBA, and the two is the development of airport group. However, the two centers are not isolated. But a unity of complementary and coordinated development. City cluster is " $9+2$ ", but there are mature airports in Guangzhou, Shenzhen, Zhuhai, Huizhou, Foshan, Hong Kong and Macao. The two airports under construction and the four surrounding airports form an airport group, which can promote the development of city cluster in GBA through the development of the airport.

\subsubsection{Intelligent collaboration among industries}

Both "city cluster + airport group" need to realize comprehensive construction and development. It is necessary to invest logistics and transportation, administrative office, education and scientific research, production and manufacturing, scientific and technological innovation, electronic chemical industry, residential life, finance

al investment, tourism exhibition, leisure and entertainment, health care, ecological and environmental protection and other industries into "airport group + city cluster", so as to make it a multi-functional and all-round construction group. Of course, it is not a random investment, but a key and tendentious setting of industries based on location, positioning, resources, history and other factors.

\subsubsection{Intelligent collaboration within and outside the two groups}

When the development of "city cluster + airport group" in GBA is relatively mature, it is necessary to cooperate with other airport group for coordinated development. Based on airport group in GBA, supplemented by five airport groups, such as Beibu Bay, Hangzhou Bay, Laizhou Bay, Bohai Bay and Liaodong Bay, six airport groups are mutually available, efficient cooperation and intelligent cooperation to help economic development.

\section{INTELLIGENT COORDINATED DEVELOPMENT STRATEGY}

The following is the actual operation data of various indicators in GBA, as shown in table 1-4. GBA covers more than 56000 hectares, with a total resident population of 69.5683 million and a total economic output of more than 10 trillion yuan. It is the largest Bay Area in the world. GBA has the smallest area and the smallest population, but its GDP is relatively high, and its urbanization rate accounts for the highest proportion, indicating that GBA has a stable development and rapid development in the future. Table 3 shows the comparison between GBA and the other three big bay areas in the world [8]. It can be seen that although the construction time of GBA is not long and mature, its development speed and potential are incalculable. Table 4 shows that the airport group has a high contribution to the economic development of GBA, and it is also the key part of the development of Intelligent Collaborative System in GBA in the future. In view of the above data, the construction of "city cluster + airport group" in GBA intelligent collaborative system needs to be supplemented with corresponding supporting measures.

Table1. Economic development indicators of cities in GBA in 2018

\begin{tabular}{|c|c|c|c|c|c|c|c|c|c|c|c|}
\hline city & $\begin{array}{c}\text { Guang } \\
\text { zhou }\end{array}$ & $\begin{array}{l}\text { Shen } \\
\text { zhen }\end{array}$ & $\begin{array}{l}\text { Zhu } \\
\text { hai }\end{array}$ & $\begin{array}{l}\text { Dong } \\
\text { guan }\end{array}$ & $\begin{array}{l}\text { Fo } \\
\text { shan }\end{array}$ & $\begin{array}{l}\text { Jiang } \\
\text { men }\end{array}$ & $\begin{array}{c}\text { Zhong } \\
\text { shan }\end{array}$ & $\begin{array}{l}\text { Hui } \\
\text { zhou }\end{array}$ & $\begin{array}{l}\text { Zhao } \\
\text { qing }\end{array}$ & $\begin{array}{l}\text { Hong } \\
\text { kong }\end{array}$ & Makao \\
\hline $\begin{array}{c}\text { GDP(100 } \\
\text { million yuan) }\end{array}$ & 22859 & 24222 & 2915 & 8279 & 9936 & 2900 & 3633 & 4103 & 2202 & 24022 & 3609 \\
\hline $\begin{array}{l}\text { GDPgrowth } \\
\text { rate }(\%)\end{array}$ & 6.2 & 7.6 & 8 & 7.4 & 6.3 & 7.8 & 5.9 & 6 & 6.6 & 3 & 4.7 \\
\hline
\end{tabular}

Table2. Comparison of major city cluster indicators in China in 2018

\begin{tabular}{|c|c|c|c|c|}
\hline & $\begin{array}{c}\text { Pearl River } \\
\text { Delta }\end{array}$ & $\begin{array}{l}\text { Beijing } \\
\text { Tianjin } \\
\text { Hebei }\end{array}$ & $\begin{array}{c}\text { Yangtze } \\
\text { River Delta }\end{array}$ & $\begin{array}{l}\text { Chengdu } \\
\text { Chongqing }\end{array}$ \\
\hline Area (10000 square kilometers) & 5.5 & 21.5 & 21.2 & 18.5 \\
\hline Permanent population (100 million) & 0.6 & 1.1 & 1.5 & 1.0 \\
\hline Total GDP (trillion yuan) & 8.1 & 8.5 & 21 & 5.8 \\
\hline Urbanization rate $(\%)$ & 85.3 & 65.8 & 67.38 & 53.8 \\
\hline
\end{tabular}


Table3. Index comparison of major Bay areas in the world in 2018

\begin{tabular}{lcccc}
\hline & GBA & $\begin{array}{c}\text { Tokyo Bay } \\
\text { Area }\end{array}$ & $\begin{array}{c}\text { New York } \\
\text { Bay Area }\end{array}$ & $\begin{array}{c}\text { San Francisco } \\
\text { Bay Area }\end{array}$ \\
\hline Area (10000 square kilometers) & 5.65 & 3.67 & 2.14 & 1.8 \\
Population (million) & 71.12 & 44 & 20.2 & 7.7 \\
Total GDP (trillion US dollars) & 1.39 & 1.86 & 1.45 & 0.82 \\
GDP growth (\%) & 7.9 & 3.5 & 3.6 & 2.7 \\
Proportion of GDP in China (\%) & 12 & 26.4 & 8 & 4.3 \\
GDP per capita (USD 10000) & 2.05 & 4.28 & 6.2 & 11.47 \\
$\begin{array}{l}\text { Port container throughput } \\
\text { (10000 standard container units) }\end{array}$ & 6520 & 766 & 465 & 227 \\
$\begin{array}{l}\text { Airport passenger throughput } \\
\text { (100 million person times) }\end{array}$ & 1.75 & 1.12 & 1.3 & 0.71 \\
$\begin{array}{l}\text { Number of Fortune 500 companies } \\
\text { Proportion of tertiary industry (\%) }\end{array}$ & 17 & 60 & 22 & 28 \\
\hline \multicolumn{1}{c}{ Data source: collect relevant data } & 62.2 & 82.3 & 89.4 & 82.8 \\
\hline
\end{tabular}

Table4. Throughput of airport groups in GBA in 2018

\begin{tabular}{|c|c|c|c|c|c|c|c|c|c|}
\hline \multirow[b]{2}{*}{ Airport } & \multicolumn{3}{|c|}{ Passenger throughput (person time) } & \multicolumn{3}{|c|}{ Cargo throughput (ton) } & \multicolumn{3}{|c|}{ Take off and landing sorties (sorties) } \\
\hline & $\begin{array}{l}\text { Completed } \\
\text { this issue }\end{array}$ & $\begin{array}{c}\text { The same } \\
\text { period last } \\
\text { year }\end{array}$ & $\begin{array}{c}\text { Year on } \\
\text { year } \\
\text { growth } \\
(\%) \\
\end{array}$ & $\begin{array}{l}\text { Completed this } \\
\text { issue }\end{array}$ & $\begin{array}{c}\text { The same period } \\
\text { last year }\end{array}$ & $\begin{array}{c}\text { Year on } \\
\text { year } \\
\text { growth } \\
(\%) \\
\end{array}$ & $\begin{array}{l}\text { Completed } \\
\text { this issue }\end{array}$ & $\begin{array}{l}\text { The same } \\
\text { period } \\
\text { last year }\end{array}$ & $\begin{array}{c}\text { Year on } \\
\text { year } \\
\text { growth } \\
(\%)\end{array}$ \\
\hline Guangzhou/Baiyun & $69,720,403$ & $65,806,977$ & 5.9 & $1,890,559.997$ & $1,780,423.132$ & 6.2 & 477,364 & 465,295 & 2.6 \\
\hline Shenzhen/Bao'an & $49,348,950$ & $45,610,651$ & 8.2 & $1,218,502.178$ & $1,159,018.578$ & 5.1 & 355,907 & 340,385 & 4.6 \\
\hline Zhuhai/Jinwan & $11,220,703$ & $9,216,808$ & 21.7 & $46,392.954$ & $37,379.048$ & 24.1 & 85,380 & 74,694 & 14.3 \\
\hline Huizhou/Pingtan & $1,879,645$ & 956,858 & 96.4 & $5,501.259$ & $3,985.932$ & 38.0 & 15,110 & 8,670 & 74.3 \\
\hline Foshan/Shati & 109,228 & 471,472 & -76.8 & 128.998 & 242.526 & -46.8 & 817 & 3,381 & -75.8 \\
\hline Hongkong & $74,700,000$ & $72,867,000$ & 2.5 & $5,100,000.000$ & $4,938,000.000$ & 1.5 & 427,725 & 420,630 & 1.7 \\
\hline Jieyang/Chaoshan & $6,493,930$ & $4,851,015$ & 33.9 & $25,249.719$ & $26,271.443$ & -3.9 & 55,564 & 49,109 & 13.1 \\
\hline Zhanjiang & $2,559,507$ & $2,090,568$ & 22.4 & $5,945.053$ & $5,238.948$ & 13.5 & 28,961 & 25,487 & 13.6 \\
\hline Meizhou/Meixian & 513,000 & 397,857 & 28.8 & 198.786 & 126.859 & 56.7 & 6,486 & 5,414 & 19.8 \\
\hline
\end{tabular}

Data source: China Civil Aviation Administration issued the 2018 civil aviation airport production statistics bulletin

\subsection{Eestablishing collaborative institutions of government}

The main task of establishing an intelligent coordination organization of "city cluster + airport group" in GBA from the perspective of national government is to unify the construction content and development pace in terms of policies, policies and systems, and promote mutual accommodation and exchange, learn from each other's strengths and complement each other's weaknesses. To ensure the intelligent and collaborative development of "city cluster + airport group". Whether the coordination mechanism between "city cluster + airport group" in GBA is smooth or not is the key to the smooth coordination of the two. Therefore, it is urgent to establish the coordination mechanism between "city cluster + airport group" in GBA at the national government level. At present, the construction of city cluster in GBA is in intense progress, and the construction and development of airport group are also in progress, but both of them are basically implemented independently, and there are many barriers and obstacles in policies, systems, personnel, funds, information and other aspects on both sides. The administrative structure and management mode are different. This foundation and current situation may lead to no problem in independent operation of both parties after completion, and unified coordination and operation cannot go on. [9] Therefore, it is necessary to set up a higher-level coordination organization, rather than a simple coordination system, in the framework of the leading group of city cluster construction and the construction group of airport group in GBA. Under this coordination organization, a special project team is set up to be responsible for and intelligently coordinate two groups of the same industry, the same construction and the same resources, and finally achieve the same goal. 


\subsection{Building intelligent airport group}

The development of city cluster in GBA is inseparable from sound airport conditions and developed airport services. In GBA, six airports have been operated. Although they have an advantage in certain quantitative indicators, they need to expand their scale and achieve economies of scale in the long term development of "one belt and one road". Therefore, the peripheral airports should be included in the "Bay Area Airport Group" to implement unified coordination and management. In terms of business, the division of labor is clear and coordinated in management to form a relatively mature airport group. Airport group in the bay area should interact with other airport groups (Beibu Bay Airport Group, Hangzhou Bay Airport Group, etc.), and realize the intelligence, convenience and coordination of multi hub airport system among airport groups through the establishment of airport intelligent coordination and supervision institutions across administrative boundaries. [10] Due to the strong substitutability in geographical location of several major airport hubs in GBA, competition and cooperation will become the main issue, so it is necessary to enhance the complementary and intelligent coordinated development of Guangzhou Baiyun airport, Hong Kong airport, Shenzhen airport and other key airports in the bay area.

\subsection{Industrial mapping intelligent collaborative development}

Governments establish a comprehensive "city cluster + airport group" in GBA, so as to keep the industry of airport group consistent with that of GBA. At present, due to the differences in geographical location, development history, cultural environment and other aspects, city cluster of GBA have formed unique advantageous industries in the long-term development process. Hong Kong's technology and financial services are leading, Shenzhen's technology innovation has advantages, Macao's tourism exhibition has characteristics, Dongguan, Foshan and other processing and manufacturing potential is great. Build the core industry chain of the urban agglomeration around the advantageous industries, and copy and promote it to the construction of airport group. The most developed airport group is air logistics. Providing advanced logistics concepts and efficient and fast logistics services to the construction of city cluster can help the city group to advance towards professional and comprehensive industrial development goals. The development of GBA is not single, and "city cluster + airport group" can't be separated. Only when the two sides do something for each other and promote each other, can the relevant industries become bigger and stronger, form the advantageous industrial chain, and then promote the rapid development of GBA.Table Styles

\subsection{Establishing platform \\ intelligent \\ cooperation}

Through the planning, layout and policy coordination of the linkage industry between the regional "city cluster + airport group" in GBA, we can realize the reasonable movement of industrial elements and the scientific sharing and allocation of resources, and promote the resource integration of "city cluster + airport group". GBA involves "one country, two systems and three independent tariff areas", which is not only its distinctive characteristics and advantages, but also has boundary problems and accommodation difficulties. There are different administrative divisions, different legal systems and different tax systems in "city cluster + airport group" of GBA, which to a large extent limits the flow of information, capital and talents, resulting in the failure of soft resources to play the maximum role. Establishing the "Bay Area Intelligent Resource Platform" to divide all resources of "city cluster + airport group" into categories and use intelligently, which is both efficient and economical. For example, high-level talents can do a certain kind of work in city cluster and share their personal information, work performance, creative innovation, etc. in the platform. During the construction and development of airport group, this person can be seconded or introduced to a great extent. We should play the role of knowledge resources and intelligent innovation to promote the intelligent coordinated development of "city cluster + airport group".

\subsection{Improve the intelligent transportation network}

The transportation network is the foundation of the development of "city cluster + airport group" in GBA. But up to now, there has not been a developed intelligent transportation network with the bay area as the core, internal connection and external radiation, which restricts the development speed and degree of "city cluster + airport group". In order to solve the traffic bottleneck, it is necessary to build air transport, railway transport, road transport, water transport and other infrastructure within "city cluster + airport group". More importantly, it is necessary to build a developed and diversified intelligent transportation network between "city cluster + airport group". [11] The formation and integration of hard resources such as transportation network and infrastructure also greatly promoted the rapid development of GBA.

\subsection{Setting up intelligent joint education institutions}

Talent is the key to enhance the core competitiveness, and also an essential factor in economic construction. The construction of "city cluster + airport group" in GBA needs a large number of high-end talents and professional talents, but the number of such talents is limited, "to seize talents is better than to create talents", and the talents cultivated by oneself will be more suitable for development. The comprehensive development of city cluster in GBA needs talents of various specialties. Therefore, city cluster should consult collectively, plan jointly, establish trans regional, international and multi- 
disciplinary universities in the bay area, train talents for the bay area, learn from the advanced school running concepts and experience of Hong Kong and Macao, and promote the intelligent coordinated development of education in the bay area. In addition, airport group also needs professional airport talents. It is necessary to establish specialized airport schools, analyze the talent training of various specialties in the airport, practice actively, reserve professional talents for the follow-up development of airport group, promote the continuous improvement and upgrading of the airport specialty, and transport airport talents for the society.

\section{CONCLUSIONS}

The intelligent cooperative system planning of the "city group + airport group" in GBA is still under constant exploration and research. Due to the lack of data in Macao and the lack of in-depth understanding of counterpart policy, the research process also has certain limitations. In the follow-up research, we will pay more attention to the current political direction, and put forward more mature ideas and strategies for the intelligent collaborative system planning of the "city cluster + airport group" in GBA.

\section{ACKNOWLEDGMENT}

The authors acknowledge the Characteristic Innovation Projects of Universities in Guangdong (2018WTSCX226), the Discipline Co-construction Project of Guangdong Province Philosophy and Social Science Planning (GD18XGL33) and the Program for Innovative Research Team of Guangdong University of Foreign Studies South China Business College (Team number: 2018TD05).

\section{REFERENCES}

1. G.S. Yang, "To find the common groundof the interests of GBA", New economy, Vol.1, issue 17, 2017.

2. X.K. Zhao, "Public services covering different institutional areas should be provided for the construction of GBA", New economy, Vol.1, issue 67, 2017.

3. M.H. Shen, "Research on the development of GBA", Urban observation, Vol. 6, issue 5-6, 2017.

4. Y. Chen, Z.H. Lin, "Grey relation analysis and coordination mechanism innovation of inter city industry coordination in GBA". Journal of Guangdong University of Finance and economics, Vol. 4, issue 33, pp. 89-97, 2018.

5. C.S. Zhou, H.H. Deng, CH.Y. Shi, "Characteristics and mechanism of coordinated development in GBA". Planner, Vol. 4, issue 34, pp. 2-12, 2018.

6. D. Li, "Study on spatial layout strategy of Shenyang airport new town", Shenyang University of architecture, 2015.

7. D. Zou, "Study on the development mode of Dalian Airport New Area Based on the theory of edge city",
Dalian University of technology, 2014.

8. S.L. Zhang, "Discussion on the development path and construction strategy of GBA: Based on the comparative analysis of three Bay areas in the world", China development, Vol. 18, issue 3, pp. 53-59, 2018.

9. X.M. Xiang, J. Yang, "Mechanism and mode of industrial coordinated development in GBA", Journal of South China Normal University (SOCIAL SCIENCE EDITION), Vol 2, pp. 17-20, 2018.

10. B. Lan, Y. Yao, "Strategic conception of Chengdu airport economic development under the background of one belt and one way strategy", Journal of Chengdu Administration College, Vol. 3, pp. 83-87, 2018.

11. Research group of Policy Research Office of Changchun municipal Party committee and government, "Research on Strategies of accelerating airport economic development in Changchun", Journal of Changchun municipal Party school, Vol. 3,pp. 58-61, 2018. 